\title{
Pseudotumoral Abdominal Tuberculosis in Immunocompetent Adults: Report of Three Cases and Review of the Literature
}

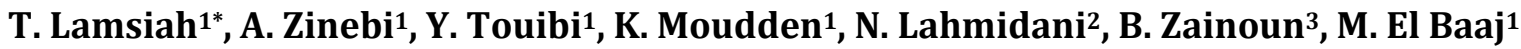 \\ ${ }^{1}$ Department of Gastroenterology and Internal Medicine, Moulay Ismail Military Hospital, Meknes, Morocco \\ ${ }^{2}$ Department of Gastroenterology, 20 Aout Hospital, Azrou, Morocco \\ ${ }^{3}$ Department of Radiology, Moulay Ismail Military Hospital, Meknes, Morocco \\ Email: *taoufik_lamsiah@yahoo.fr
}

How to cite this paper: Lamsiah, T., Zinebi, A., Touibi, Y., Moudden, K., Lahmidani, N., Zainoun, B. and El Baaj, M. (2017) Pseudotumoral Abdominal Tuberculosis in Immunocompetent Adults: Report of Three Cases and Review of the Literature. Journal of Tuberculosis Research, 5, 23-29. https://doi.org/10.4236/jtr.2017.51003

Received: January 25, 2017

Accepted: February 26, 2017

Published: March 1, 2017

Copyright ( 92017 by authors and Scientific Research Publishing Inc. This work is licensed under the Creative Commons Attribution International License (CC BY 4.0).

http://creativecommons.org/licenses/by/4.0/

\section{(c) (i) Open Access}

\begin{abstract}
Purpose: To highlight diagnostic challenges of pseudotumoral abdominal tuberculosis. Materials and methods: Three cases of pseudotumoral abdominal tuberculosis were compiled in our department between 2014 and 2015. They were aged 34 years, 42 years and 61 years respectively. They were immunocompetent and had no personal or family history of tuberculosis. Clinical presentations were non-specific, represented by abdominal pain and weight loss in the three patients and chronic diarrhea in one patient. Abdominal ultrasound and computed tomography CT were performed in all patients. Abdominal MRI was performed in one case as well as a colonoscopy. Results: Retroperitoneal tuberculosis and colic tuberculosis were noted in the 1st and 2nd case. Macro-nodular and biliary hepatic tuberculosis was retained in the third case. The diagnosis was based upon histopathology in the 3 cases showing tubercular granuloma with caseation. Anti-tuberculosis therapy was prescribed for 6 months. Evolution was favorable in all patients. Conclusion: Tuberculosis continues to present diagnostic difficulties, particularly in its pseudo-tumoral form, even in endemic tuberculosis countries like ours.
\end{abstract}

\section{Keywords}

Pseudotumoral Abdominal Tuberculosis, Colic Tuberculosis, Hepatic Tuberculosis, Retroperitoneal Tuberculosis

\section{Introduction}

Pseudotumoral abdominal tuberculosis has been rarely reported across the literature, even in endemic areas of tuberculosis [1]. Usually, the clinical and radiological presentation of the disease simulates neoplastic diseases and may cause 
delayed diagnosis for a curable disease [1].

We review in this paper the clinical presentation of three cases of pseudotumoral abdominal tuberculosis among immunocompetent adults.

\section{Case Series}

\section{Case 1:}

A 61-year old woman had a three months history of abdominal pain and weight loss of $13 \mathrm{Kg}$. No abnormalities were detected in her physical examination. Blood examination revealed an inflammatory syndrome ( $\mathrm{C}$ reactive protein $45 \mathrm{mg} / \mathrm{l}(\mathrm{N}<5 \mathrm{mg} / \mathrm{l}) ;$ erythrocyte sedimentation rate $52 \mathrm{~mm} /$ hour $(\mathrm{N}<8$ $\mathrm{mm} /$ hour), blood count was normal and viral serology (hepatitis B virus HBV, virus hepatitis $\mathrm{C}$ virus HCV, human immunodeficiency virus HIV) were negative. The abdominal ultrasonography and CT-scan found a retroperitoneal mass measuring $45 \mathrm{~mm}$ (Figure 1). The CT-scan showed a hypodense area within the mass.

The scan-guided biopsy of the retroperitoneal mass confirmed the diagnosis of tuberculosis (granulomas with caseous necrosis at the histopathological examination).

The tuberculin testing was negative and the chest X-ray was normal.

The patient received six months of tuberculosis chemotherapy based on the protocol of rifampicin, isoniazid, pyrazinamide and ethambutol during 2 months followed by rifampicicn and isoniazid during 4 months. The treatment was well tolerated. The follow up was uneventful. The patient recovered completely. The CT-Scan was normal at the end of treatment. The patient is healthy 10 months later.

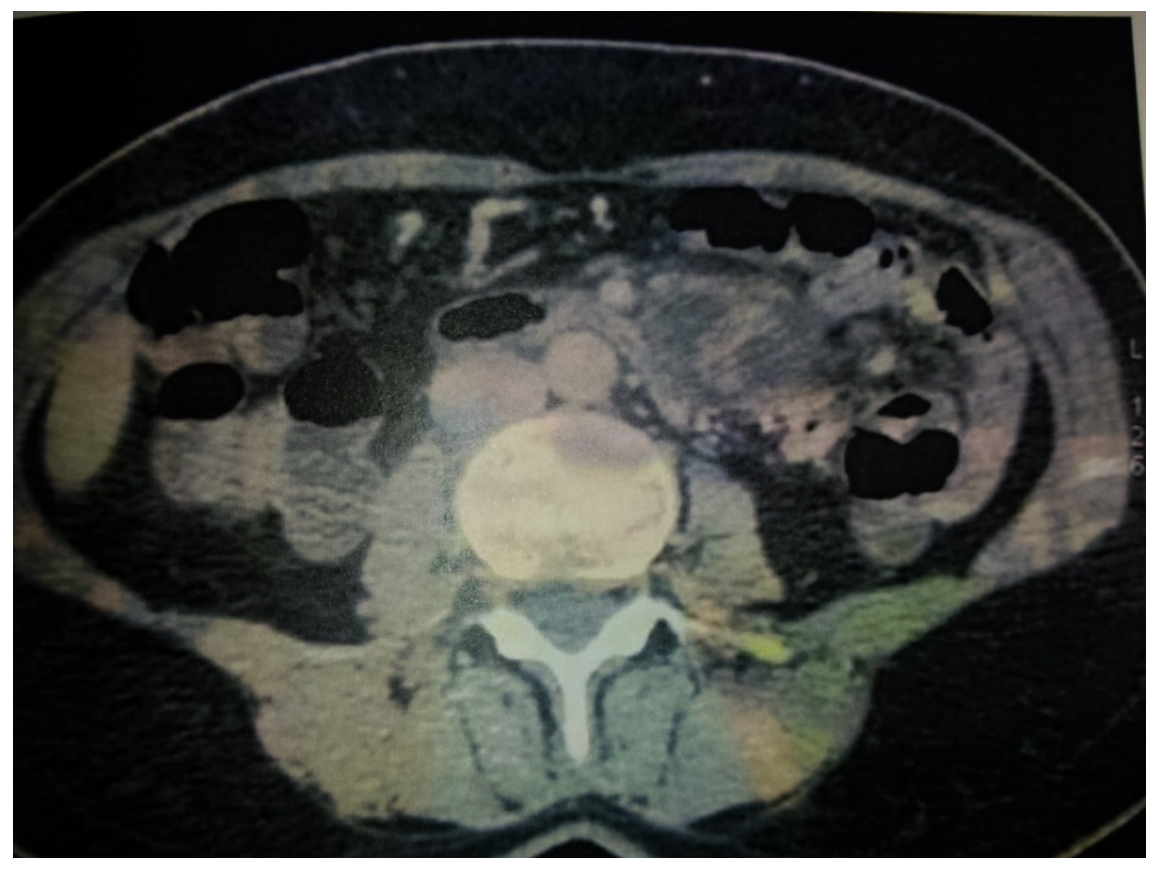

Figure 1. Abdominal CT scan of a retroperitoneal mass with hypodense area indicated by marker. 


\section{Case 2:}

A 34 year old woman was admitted for chronic diarrhea, abdominal pain and weigh loss of $10 \mathrm{~kg}$ evolving since 4 months.

The clinical examination was normal. The blood examination showed a non specific inflammatory syndrome (C reactive protein $75 \mathrm{mg} / \mathrm{l}$ ) and viral serology (HBV, HCV, HIV) were negative. The CT-scan revealed the presence of an irregular thickening of the right colon (Figure 2). Colonoscopy showed a pseudo polypoid lesion with stenosis of the right colon (Figure 3). The histopathological examination concluded to the presence of caseating granulomas. The tuberculin testing was negative and the chest X-ray was normal.

Anti-tubercular drugs were prescribed and well tolerated for 6 months. The CT-scan was normal at the end of treatment.

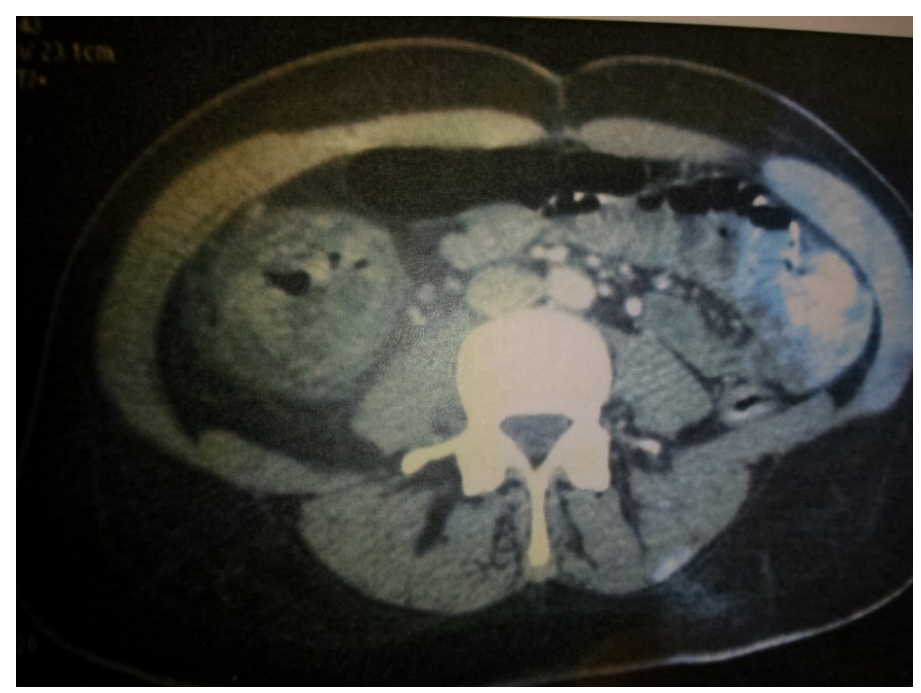

Figure 2. Abdominal CT-Scan of an irregular thickening of the right colon indicated by marker.

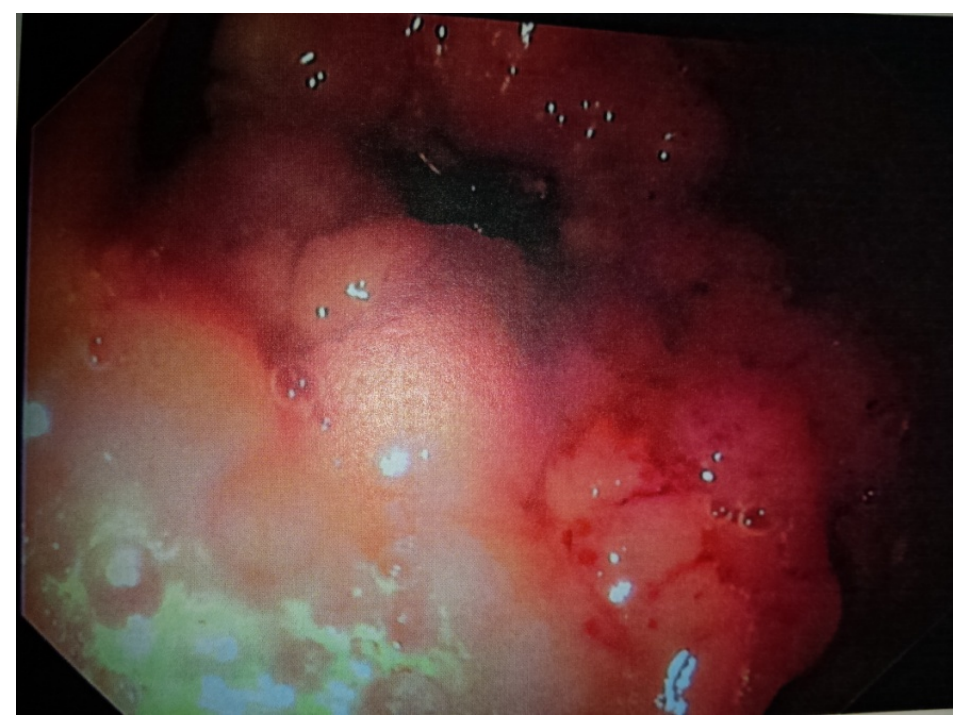

Figure 3. Colonoscopy showing a pseudo polypoide lesion with stenosis of the right colon. 


\section{Case 3:}

A 42-year-old patient with no previous medical history, hospitalized for abdominal pain and $15 \mathrm{~kg}$ weight loss without fever raise for 4 months. Clinical examination has revealed hepatomegaly slightly tender with minimal splenomegaly without signs of portal hypertension or hepatocellular insufficiency and without peripheral adenopathies. The biological examination revealed an elevation of amino transferasease at 3 times ULN. Anicteric cholestasis (gamma glutamyltransferase 4 times ULN, alkaline phosphatase 3 times ULN, total bilirubin at $15 \mathrm{mg} / \mathrm{l}$, conjugated bilirubin at $10 \mathrm{mg} / \mathrm{l}$ ), viral serologies (HBV, HCV, HIV) were negative. The CRP was at $85 \mathrm{mg} / \mathrm{l}$. The ultrasound and then the abdominal CT scan showed a mass of the left liver and splenomegaly (Figure 4). Thoracic CT scan was normal. The tuberculin testing was negative.

An echo-guided biopsy of the hepatic mass was performed and returned in favor of sclerosing cholangitis. To support the diagnosis of sclerosing cholangitis, a Bili-MRI was requested and showed a thick left bile duct with an irregular wall showing an appearance of multiple monoliformstenoses (Figure 5(a)). The left bile duct appears to encircle the left hepatic mass (Figure 5(b)). In view of this aspect of sclerosing cholang it is associated with hepatic mass, the diagnosis of cholangiocarcinoma was raised and a second liver biopsy was performed showing an epithelioid granuloma with caseous necrosis. The diagnosis of macronodular and biliary hepatic tuberculosis was retained and the patient was placed on anti-tubecular treatment for 6 months according the same protocol. The evolution was favorable. Few weeks after the beginning of the treatment clinical status and biological parameters improved. Ultrasonography and CTScan performed at the end of therapy were normal. One year later, the patient is healthy.

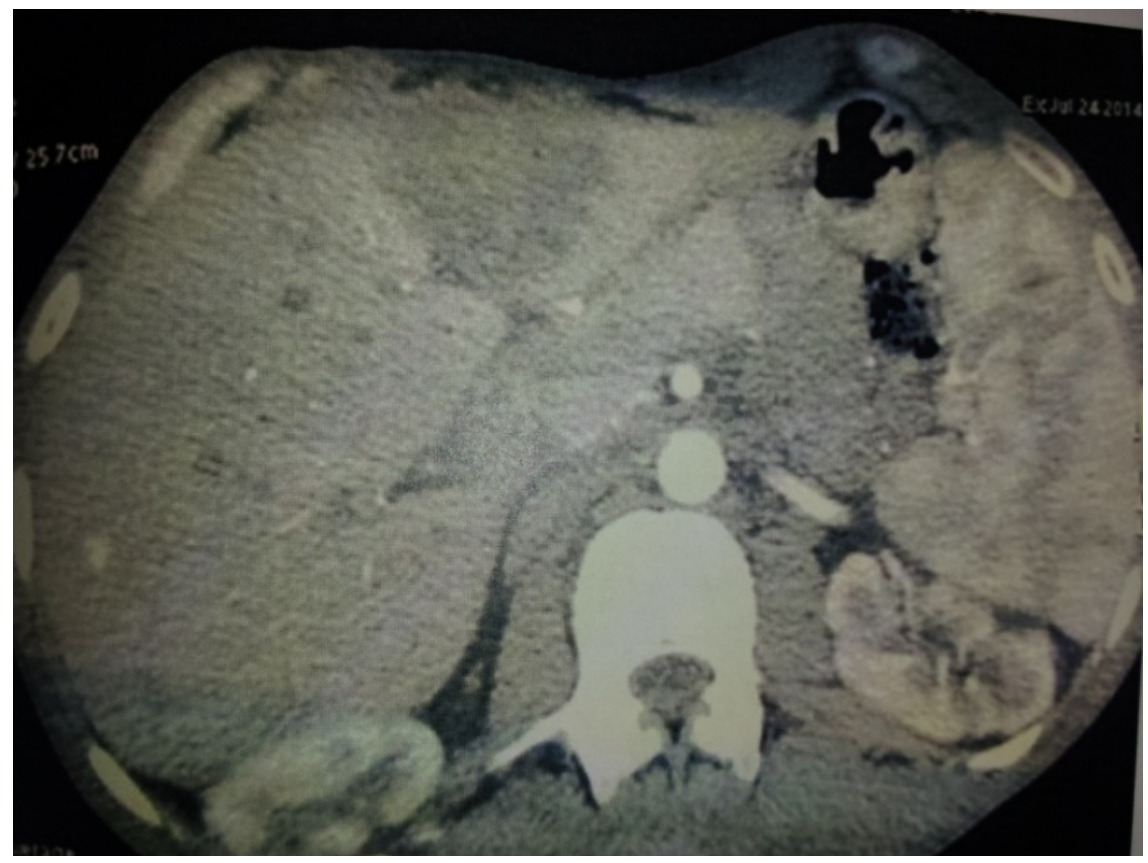

Figure 4. Abdominal CT scan showing a mass of the left liver indicated by a marker. 


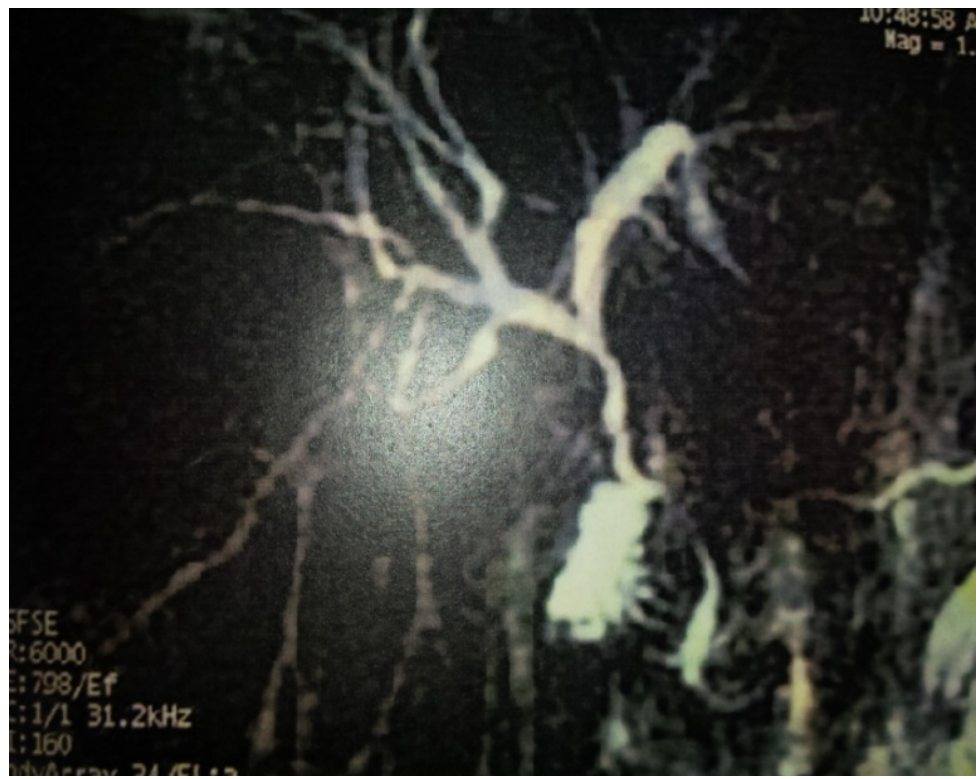

(a)

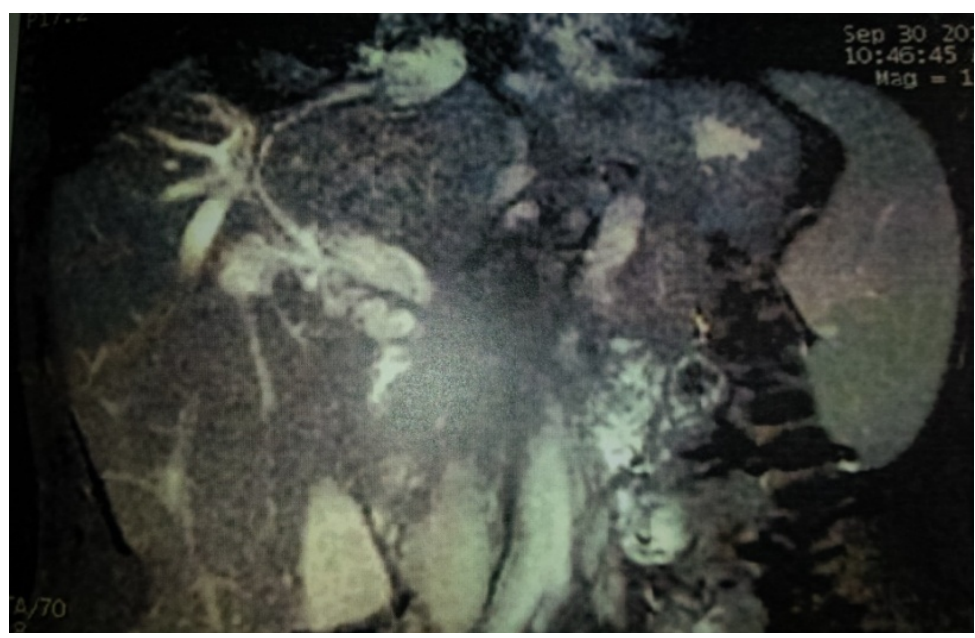

(b)

Figure 5. (a): Bili-IRM showing an irregular wall and thickening of the left bile duct; (b): Bili-IRM showing the left bile duct encircling the hepatic mass.

\section{Discussion}

Extra-pulmonary tuberculosis is defined as the involvement of an organ other than the lung by the bacillus of Koch BK. It can be isolated or associated with pulmonary involvement. It represents $52 \%$ of tuberculosis reported in Morocco in 2015 [2]. Abdominal tuberculosis is a relatively frequent extra pulmonary form. It represents $5 \%$ to $10 \%$ of all locations [3]. This frequency could double to triple in HIV positive patients [3] [4]. In the abdominal stage, ganglionic affection is the most frequent one, other localizations concern the digestive tract such as the peritoneum, the liver and the spleen [5]. Abdominal tuberculosis can have different clinical and radiological aspects [6]. However, a radiological aspect suggestive of tumor pathology is reported in approximately 5\% [3] which may present diagnostic difficulties. 
Pseudo-tumor colon tuberculosis can mimic colon cancer [7]. The clinical picture is represented by an alteration of the general state, abdominal pain and transit disorders [7]. The forms revealed by a complication such as occlusion, haemorrhage or perforation are possible and rarely described [8] [9]. In imaging, the diagnosis of pseudo-tumor tuberculosis is very difficult [5]. The CT-scan aspect of agglutinated loops, parietal infiltration and neighboring organs, and even peritoneal nodules is always evocative of cancer in the first place [3] [5]. Endoscopy may show a polypoid mass suggestive of a colon tumor [10]. Biopsy samples obtained during colonoscopy can be analyzed in bacteriology and histology [11]. The diagnosis is sometimes retained only by postoperative pathology [11].

Hepatic tuberculosis in its macronodular form first evokes a primary or secondary cancer of the liver [12]. It is usually discovered on the occasion of nonspecific clinical signs (fever, weight loss, abdominal pain) [12] [13]. Clinical examination may be normal or return to hepatomegaly. Liver tests may be disrupted (cytolysis, cholestasis) [12] [13]. An inflammatory syndrome is often present. Abdominal ultrasound shows one or more hypoechoic nodules [14]. In tomodensitometry the lesions are often hypodense and sometimes with a peripheral enhancement after injection of the contrast product [14]. In MRI various aspects can be noted [14]. In the case of tuberculous cholangitis, canalicular lesions may be individualized as it was the case in our patient. The discovery of a hepatic mass associated with a radiological and histological cholangitis raises a discussion of intrahepatic cholangiocarcinom diagnosis. The discovery of a granuloma with caseous necrosis in the histological examination of the radioguided biopsy makes it possible to retain the diagnosis. Otherwise surgery may be necessary to make the diagnosis sure [12].

Retroperitoneal tuberculosis usually occurs in the form of adenopathies smaller than those of lymphomas or ganglionic metastases, with little confluence [15]. At the CT scan, these adenopathies have a hypodense, necrotic center and they are enhanced in the periphery [15]. However, when they are in the form of a large mass with a necrotic center, as was the case with our patient, the differential diagnosis with retroperitoneal tumors and especially with leimyosarcoma proves difficult or even impossible with imaging [15]. The diagnosis can only be made after percutaneous biopsy or even surgical exploration.

The myriad clinical, radiological and endoscopical presentations of pseudo tumoral abdominal tuberculosis continue to be a source of diagnostic challenge as illustrated in our 3 cases. As observed in our cases serie, non surgical diagnosis allowed avoiding exploratory laparotomy

\section{Conclusion}

Abdominal tuberculosis can result in a clinical and morphological picture that can lead to confusion with tumor pathology [1] [3]. The discovery of a tuberculoid granuloma in the histological examination of biopsies obtained endoscopically or under radiological guidance makes it possible to set right the diagnosis. Otherwise, surgery may be necessary in case of any diagnosis or complications [11]. 


\section{References}

[1] El Barni, R., Lahkim, M. and Achour, A. (2012) Abdominale Pseudo-Tumoral Tuberculosis. Pan African Medical Journal, 13, 32.

[2] Direction of Epidemiology and Disease Control, Ministry of Health (2015) Epidemiological Situation of Tuberculosis in Morocco. Direction of Epidemiology and Disease Control, Ministry of Health, Rabat.

[3] Romand, F., Gaudin, J.L., Bobinchon, R. and Souquet, J.C. (1997) Abdominal Tuberculosis of Pseudotumor Aspect. Presse Medicale, 26, 1717-1721.

[4] Verspyck, E., Struder, C., Wendum, D., Bourgeois, D., Lariven, S. and Marpeau, L. (1997) Peritoneal Tuberculosis. Annales de Chirurgie, 51, 357-378.

[5] Hablani, N., Souei, M.M., Tlili, G.K., Jemni, G.H., Abdallah, S. and Bel Hadj, H.R. (2005) Pseudotumoral form of Abdominal Tuberculosis: Report of Four Cases. Journal of Radiology, 86, 1021-1025. https://doi.org/10.1016/S0221-0363(05)81486-6

[6] Jemni, H., Bellara, I., Tlili, K., et al. (2000) Tuberculous Mesenteric Lymhadenitis: A Case Report. Journal of Radiology, 81, 1715-1717.

[7] Singh, V., Kumar, P., Kamal, J., Prakash, V., Waiphei, K. and Singh, K. (1996) Clinicocolonoscopic Profile of Colonic Tuberculosis. The American Journal of Gastroenterology, 91, 565-568.

[8] Najah, S., Birkowske, K.S. and Bouricha, M. (1977) Acute Intestinal Occlusion Caused by Hypertrophic Tuberculosis of the Transverse Colon. La Tunisie Medicale, 55, 179-181.

[9] Monkemuller, K.E. and Lewis, J.B.J. (1996) Massive Rectal Bleeding from Colonic Tuberculosis. The American Journal of Gastroenterology, 91, 1439-1441.

[10] Mukewar, S., Mukewar, S., Ravi, R., Prasad, A.S. and Dua, K. (2012) Colon Tuberculosis: Endoscopic Features and Prospective Endoscopic Follow up after Anti-Tuberculosis Treatment. Clinical and Translational Gastroenterology, 3, e24. https://doi.org/10.1038/ctg.2012.19

[11] Ibrarallah, M., Mohan, A., Sakari, A., Srinivas, M. and Mishra, A. (2002) Abdominal Tuberculosis: Diagnosis by Laparoscopy and Colonoscopy. Tropical Gastroenterology, 23, 150-153.

[12] Wu, Z., Wang, W.-L., Zhu, Y., Cheng, J.-W., Dong, J., Li, M.-X., Yu, L., Lv, Y. and Wang, B. (2013) Diagnosis and Treatment of Hepatic Tuberculosis: Report of Five Cases and Review of Literature. International Journal of Clinical and Experimental Medicine, 6, 845-850.

[13] Kharasse, G., Soufi, M., Berekhli, H., Intissar, H., Bouziane, M. and Ismaili, Z. (2014) Primary Tuberculoma of the Liver: A Case Report and Literature Review. The Pan African Medical Journal, 19, 321. https://doi.org/10.11604/pamj.2014.19.321.5107

[14] Nassar, I., Errabih, I., Bouklata, S., Hammani, L., Krami, H.E., Lola, N., Ajana, A. and Imani, F. (2008) Primary Tuberculosis of the Liver, Ten Cases Reports. Feuillets de Radiologie, 48, 203-207. https://doi.org/10.1016/S0181-9801(08)74058-2

[15] Merran, S., Karila-Cohen, P. and Vieillefond, A. (2004) Primary Retroperitoneal Tumors in Adults. Journal of Radiology, 85, 252-264.

https://doi.org/10.1016/S0221-0363(04)97576-2 
Submit or recommend next manuscript to SCIRP and we will provide best service for you:

Accepting pre-submission inquiries through Email, Facebook, LinkedIn, Twitter, etc. A wide selection of journals (inclusive of 9 subjects, more than 200 journals)

Providing 24-hour high-quality service

User-friendly online submission system

Fair and swift peer-review system

Efficient typesetting and proofreading procedure

Display of the result of downloads and visits, as well as the number of cited articles Maximum dissemination of your research work

Submit your manuscript at: http://papersubmission.scirp.org/

Or contact 迆@scirp.org 